\title{
Impact of a rapid access protocol on decreasing door-to-balloon time in acute ST elevation myocardial infarction
}

\author{
Jaelyn M. Caudle, MD;* Zoe Piggott, MD; ${ }^{\dagger}$ Suzanne Dostaler, MSc;§ Karen Graham, MD;* \\ Robert J. Brison, MD*
}

\begin{abstract}
Objective: Ischemic cardiovascular disease is the leading cause of death in Canada. In ST elevation myocardial infarction (STEMI), time to reperfusion is a key determinant in reducing morbidity and mortality with percutaneous coronary intervention $(\mathrm{PCI})$ being the preferred reperfusion strategy. Where $\mathrm{PCl}$ is available, delays to definitive care include times to electrocardiogram (ECG) diagnosis and cardiovascular laboratory access. In 2004, the Cardiac Care Network of Ontario recommended implementation of an emergency department (ED) protocol to reduce reperfusion time by transporting patients with STEMI directly to the nearest catheterization laboratory. The model was implemented in Frontenac County in April 2005. The objective of this study was to assess the effectiveness of a protocol for rapid access to $\mathrm{PCl}$ in reducing door-to-balloon times in STEMI.

Methods: Two 1-year periods before and after implementation of a rapid access to $\mathrm{PCl}$ protocol (ending March 2005 and June 2006, respectively) were studied. Administrative databases were used to identify all subjects with STEMI who were transported by regional emergency medical services (EMS) and received emergent $\mathrm{PCl}$. The primary outcome measure was time from ED arrival to first balloon inflation (door-to-balloon time). Times are presented as medians and interquartile ranges (IQRs). Statistical comparisons were made using the Mann-Whitney $U$ test and presented graphically with Kaplan-Meier curves.

Results: Patients transported under the rapid access protocol $(n=39)$ were compared with historical controls $(n=42)$. Median door-to-balloon time was reduced from 87 minutes (IQR 67-108) preprotocol to 62 minutes (IQR 40-80) postprotocol $(p<0.001)$.

Conclusion: In our region, implementation of an EMS protocol for rapid access to $\mathrm{PCl}$ significantly reduced time to reperfusion for patients with STEMI.
\end{abstract}

Keywords: transfer protocol, acute myocardial infarction, prehospital

RÉSUMÉ

Objectif : Les maladies cardio-vasculaires ischémiques sont la principale cause de décès au Canada. Dans les cas d'infarctus du myocarde avec sus-décalage du segment ST (STEMI), le temps avant la reperfusion est un facteur déterminant dans la réduction de la morbidité et de la mortalité,

From the *Department of Emergency Medicine, Queen's University, Kingston, Ont., the tDepartment of Emergency Medicine, University of Manitoba, Winnipeg, Man., and §Kingston General Hospital Clinical Research Centre, Kingston, Ont.

Submitted Nov. 7, 2007; Revised June 26, 2008; Accepted Aug. 13, 2008

This article has been peer reviewed.

CJEM 2009;11(1):29-35 
I'intervention coronaire percutanée (ICP) constituant la meilleure stratégie de reperfusion. Dans les établissements qui pratiquent les ICP, les retards avant la prise en charge définitive comprennent le temps nécessaire au diagnostic de l'électrocardiogramme et l'accès au laboratoire cardiovasculaire. En 2004, le Réseau de soins cardiaques de l'Ontario a recommandé la mise en œuvre d'un protocole à l'intention des services d'urgence afin de réduire le temps avant la reperfusion en transportant les patients avec un STEMI directement au laboratoire de cathétérisme le plus proche. Le modèle a été adopté dans le comté de Frontenac en avril 2005. L'objectif de cette étude était d'évaluer l'efficacité d'un protocole pour l'accès rapide à une ICP en réduisant le temps entre l'arrivée à l'urgence et le gonflement du ballonnet dans les cas de STEMI.

Méthodes: Nous avons étudié 2 périodes d'un an avant et après la mise en œuvre d'un protocole d'accès rapide à I'ICP (se terminant respectivement en mars 2005 et en juin 2006). Nous avons utilisé des bases de données administratives pour repérer tous les patients atteints d'un STEMI qui ont été transportés par les services médicaux d'urgence (SMU) régionaux et ont fait l'objet d'une ICP imminente. La principale mesure des résultats a été le temps d'arrivée à l'urgence jusqu'au gonflement du ballonnet (arrivée-à-ballonnet). Les mesures de temps ont été exprimées en termes de médianes et d'écarts interquartiles. Les comparaisons statistiques ont été effectuées à l'aide du test de Mann-Whitney et présentées graphiquement selon la méthode de Kaplan-Meier.

Résultats : Nous avons comparé les patients transportés selon le protocole d'accès rapide $(n=39)$ aux groupes témoins historiques $(n=42)$. Nous avons observé une réduction du délai médian " arrivée-à-ballonnet », qui est passé de 87 minutes avant le protocole (écart interquartile de 67 à $108 \mathrm{~min}$ ) à 62 minutes (écart interquartile de 40 à $80 \mathrm{~min}$ ) après sa mise en œuvre $(p<0,001)$.

Conclusion : Dans notre région, la mise en œuvre d'un protocole d'accès rapide à une ICP a réduit de manière significative le temps avant la reperfusion pour les patients atteints de STEMI.

\section{Introduction}

Ischemic cardiovascular disease is the leading cause of death in Canada. ${ }^{1}$ In ST elevation myocardial infarction (STEMI), time to reperfusion is a key determinant of outcome. In the first hours after symptom onset, shorter time to reperfusion is associated with improved survival. This is true whether it is achieved through thrombolytic therapy or percutaneous coronary intervention (PCI). ${ }^{2,3}$ The goal of either strategy is to reopen the occluded artery, thereby limiting infarct size, reducing left ventricular dysfunction and improving survival. ${ }^{4}$ Guidelines recommend goals of a door-to-needle time of less than 30 minutes in thrombolysis and a door-to-balloon time of less than 90 minutes in PCI. ${ }^{5,6}$ In a recent meta-analysis involving data from 7739 patients, PCI was shown to reduce mortality as well as risk of nonfatal infarction and stroke when compared with thrombolysis. ${ }^{7}$ Improved outcomes are maintained irrespective of thrombolytic agent used, even when including patients transferred for primary PCI. ${ }^{8-10}$

Delays in time to treatment most commonly result from a patient's delay in seeking medical care. ${ }^{2}$ Reported median times for patients with STEMI from symptom onset to emergency department (ED) arrival range from 2.0 to 6.4 hours. Public education campaigns to reduce this time interval have had variable impact. ${ }^{11,12}$ For the patients who access EMS, additional delays relate to the time to electrocardiogram (ECG) diagnosis and access to definitive care in a cardiovascular laboratory. ${ }^{2}$ Use of prehospital ECGs has been shown to decrease in-hospital time to treatment and improve survival because of earlier diagnosis and ED notification. ${ }^{13,14}$ A study by Whitbread and colleagues ${ }^{15}$ showed that paramedic 12-lead ECG interpretation of ST elevation is highly sensitive (0.97) and specific (0.91) when compared with cardiologist interpretation.

Notification of the cardiovascular laboratory while the patient is en route to hospital can reduce the mean door-toballoon time by 15.4 minutes. Emergency physician activation of the cardiovascular laboratory, rather than waiting for the cardiologist, can produce a mean time saving of 8.2 minutes. ${ }^{16}$ Prehospital protocols that allow EMS personnel to transfer STEMI patients to the nearest cardiovascular laboratory, bypassing nearer hospitals, have been suggested as another strategy to reduce time to primary PCI. ${ }^{16}$ Leung and coworkers ${ }^{17}$ demonstrated a reduction in median door-to-balloon time of 55 minutes (95 v. 40 min; $p<0.001)$ with such a protocol. The majority of time saved (median $43.5 \mathrm{~min}$ ) occurred in the interval between ED triage and arrival at the catheterization laboratory. There are no reports to date of prehospital protocols that recommend direct transit through the ED to the cardiovascular laboratory within a centre with PCI capability.

Most cardiovascular centres in Canada do not meet the American Heart Association recommended goal of a doorto-balloon time of less than 90 minutes. A 2005 report showed this target time was achieved in only $45 \%$ of 
patients. ${ }^{18}$ In 2004, the Cardiac Care Network of Ontario recommended implementation of a prehospital bypass protocol to reduce time to reperfusion by transporting patients with STEMI directly to the nearest catheterization laboratory. The model was implemented in Frontenac County in April 2005. This study was designed to assess whether the institution of such a protocol would be effective in reducing hospital door-to-balloon times.

\section{Methods}

Kingston General Hospital is within an academic health sciences centre that provides primary and the sole secondary cardiovascular (catheterization) laboratory services to a regional population of 150000 .

\section{Rapid access percutaneous coronary intervention protocol}

Frontenac County EMS, in conjunction with the Departments of Emergency Medicine and Cardiology at Kingston General Hospital, implemented a rapid access PCI protocol in April 2005. In our study, we included patients transported by Frontenac EMS whose primary complaint was chest pain of less than 12 hours duration and who had a prehospital 12-lead ECG with a computer reading of "acute MI." Paramedics contacted either the cardiovascular laboratory directly (weekday hours 08:00-16:00) or the base hospital physician (evenings 16:00-08:00, weekends and statutory holidays) to activate the PCI protocol. If the cardiovascular laboratory was immediately available on the patient's arrival at the hospital, EMS would proceed directly to the laboratory. After hours, or if the catheterization team was delayed, the ED team would receive the patient and initiate standard STEMI care. In both study phases, primary PCI was the standard for definitive care of STEMI. Cardiovascular laboratory resources remained unchanged before and after protocol implementation.

We excluded patients with atypical presenting complaints (e.g., respiratory distress, abdominal pain) and those who were transferred from peripheral hospitals for primary or facilitated PCI (i.e., thrombolysis at a peripheral site) from the study. Prior to implementation Frontenac County basic and advanced care paramedics received 6 hours of training on the 12-lead ECG diagnosis of STEMI criteria and 2 hours on the proposed PCI protocol. We allowed a 2-month window for the paramedic learning curve after implementing the protocol. Regional paramedics received their PCI protocol training over the months preceding the official implementation date, which resulted in some patients being managed under the protocol before official implementation. These patients were included in the preimplementation phase in our analysis. Prehospital-12-lead ECG was obtained using a LifePak 12 defibrillator/monitor (version 130, Physio-Control, Inc.) and software.

\section{Study design}

We conducted a before and after study of 1-year intervals ending Mar. 31, 2005, and June 30, 2006, respectively. All patients with STEMI who were transported by Frontenac EMS and who received balloon inflation PCI were included. If they did not receive balloon inflation, they were excluded. Patients were identified using the cardiovascular laboratory, hospital discharge and National Ambulatory Care Reporting System (NACRS) databases. Data were abstracted from prehospital and inhospital medical records. The cardiovascular laboratory database is maintained by manual input of consecutive patient demographic data, treatment times, complications and product information at the time of treatment. Emergent PCIs are recorded using a unique clinical record identifier. Database accuracy is monitored monthly by the cardiovascular laboratory manager. For each hospital encounter, the NACRS code physician identified diagnosis using codes from the International Classification of Diseases, Canadian Edition, 10th revision (ICD-10). Data were abstracted by a trained abstractor (Z.P.) using a standard data form with review of each by the principle investigator (J.C.). Coding disagreements were reviewed by a third party (K.G.) and resolved by consensus.

\section{Statistical analysis}

The primary outcome measure was time from ED arrival to first balloon inflation (door-to-balloon time). Secondary outcome measures included the interval times for: 911 to scene arrival, time spent at the scene, transport time, ED treatment and transit and catheterization laboratory arrival to first balloon inflation. Regular hours were defined as weekday cardiovascular laboratory hours 08:00-16:00. All hours outside these, plus statutory or nursing union holidays were defined as after-hours. Statistical comparisons were made using the Mann-Whitney $U$ test and Kaplan-Meier survival analysis. We also assessed the proportion of patients receiving PCI within the recommended 90-minute door-to-balloon time and subsets of clinically relevant intervals (0-30 min, 31-60 min, 61-90 min and $>90 \mathrm{~min}$ ). Demographic and descriptive data were reported using percentages and compared using Fisher exact test for categorical variables and $t$ tests for continuous variables. Statistical analyses were performed using SPSS version 14 
(SPSS Inc.). The institutional ethics review board at Queen's University approved this study.

\section{Results}

Chart review was completed on 97 patients who met the inclusion criteria for the study. Fourteen patients with STEMI had an angiogram, but did not receive PCI (unstentable lesion $=8$, death before PCI $=2$, spontaneous reperfusion $=1$, no lesion $=3$ ). These patients were excluded from analysis as they lacked the primary outcome measure (door-to-balloon time). For 2 patients, data were incomplete, thus precluding analysis. The final data set included 81 patients: 42 in the preprotocol group and 39 in the postprotocol group. Two patients in the preimplementation phase were managed using the rapid access protocol.

Table 1. Baseline patient demographic and logistical characteristics of $\mathbf{8 1}$ patients with ST-segment elevation myocardial infarction who received primary percutaneous coronary intervention before and after implementation of a rapid access protocol

\begin{tabular}{|c|c|c|}
\hline \multirow[b]{2}{*}{ Characteristic*† } & \multicolumn{2}{|c|}{$\begin{array}{l}\text { No. of patients, before and } \\
\text { after rapid access protocol }\end{array}$} \\
\hline & $\begin{array}{c}\text { Before, } \\
n=42\end{array}$ & $\begin{array}{l}\text { After } \\
n=39\end{array}$ \\
\hline Male sex & 24 & 30 \\
\hline \multicolumn{3}{|l|}{ Age, yr } \\
\hline 20-39 & 1 & 2 \\
\hline $40-59$ & 19 & 18 \\
\hline $60-79$ & 15 & 14 \\
\hline$\geq 80$ & 7 & 5 \\
\hline \multicolumn{3}{|l|}{ Medical history } \\
\hline CAD/angina & 16 & 11 \\
\hline Diabetes mellitus & 6 & 4 \\
\hline \multicolumn{3}{|c|}{ First measured heart rate } \\
\hline Mean (SD) & 73 & 72 \\
\hline Median (IQR) & 64 & 72 \\
\hline Range & $38-260$ & $36-105$ \\
\hline \multicolumn{3}{|l|}{ Crew type } \\
\hline Basic care & 13 & 12 \\
\hline Advanced care & 29 & 27 \\
\hline \multicolumn{3}{|c|}{ Catheterization lab hours } \\
\hline Regular & 12 & 14 \\
\hline After hours & 30 & 25 \\
\hline \multicolumn{3}{|c|}{ Procedural complications } \\
\hline Defibrillation & 2 & 1 \\
\hline Pacemaker & 4 & 1 \\
\hline IABP & 0 & 1 \\
\hline None & 36 & 36 \\
\hline
\end{tabular}

$C A D=$ coronary artery disease; $I A B P=$ intra-aortic balloon pump;

$\mathrm{IQR}=$ interquartile range; $\mathrm{SD}=$ standard deviation

*There were no significant differences in any of these proportions between groups.

tFisher exact test, $p>0.05 ; t$ test for mean heart rate.
The groups had similar demographic and PCI logistical characteristics. Apparent differences in the distributions of sex and history of coronary artery disease were not statistically significant (Table 1).

Following implementation of the rapid access protocol, there was a statistically significant reduction in median door-to-balloon time of 25 minutes; 87 minutes (interquartile range [IQR] 67-108) preprotocol implementation compared with 62 minutes (IQR 40-80) postprotocol $(p<0.001)$. Most of the time that was saved occurred during the ED treatment time; 63 (IQR 47-83) minutes preprotocol versus 39 (IQR 18-57) minutes postprotocol $(p<0.001)$. Nine patients were transported directly to the cardiovascular laboratory, or had minimal time $(<15 \mathrm{~min})$ in the ED: 7 during regular hours and 2 after-hours. The remaining patients, overall, had shorter stays (Table 2). No statistically significant difference in EMS arrival, time at the scene, transport or cardiovascular laboratory-toballoon times was noted (Table 2). Fig. 1 provides a visual presentation of the cumulative time to balloon inflation for each group using a Kaplan-Meier time series analysis $(p<0.001)$.

Before the implementation of this protocol, $52 \%$ of patients arriving by EMS failed to undergo primary PCI within the recommended 90-minute door-to-balloon time (Fig. 2). After the protocol came into effect, $82 \%$ received the intervention within 90 minutes. This improved outcome was noted regardless of the time of presentation (Table 2).

Few patients suffered complications in the cardiovascular laboratory. In the preprotocol group, 6 adverse events (i.e., unstable dysrhythmia requiring defibrillation or pacemaker insertion or both) were encountered in 6 patients. Three postprotocol patients encountered 3 adverse events (refractory hypotension requiring insertion of an intraaortic balloon pump, and defibrillation, pacemaker insertion or both for unstable dysrhythmia) (Table 1).

\section{Discussion}

Considerations in providing optimal care pertaining to reperfusion techniques and treatments are complex, and often depend on the geographic location of the patient and the specific circumstances surrounding the case. ${ }^{19}$ Several specific strategies have recently been shown to reduce time to primary PCI, among them the implementation of prehospital transfer protocols such as the one examined in this study. Despite this evidence, only a minority of hospitals in the United States and Canada actually make use of these strategies. ${ }^{20,21}$ Our study is particularly relevant to this issue, 
as it demonstrates that a rapid access protocol, which includes the potential for direct access to the cardiovascular laboratory by EMS, can successfully reduce time to reperfusion. This novel approach to an expedited transfer protocol can be readily applied as an adjunct to improving times to reperfusion in centres with few options for advanced cardiac care.

Our results show a statistically significant reduction in time to reperfusion via primary PCI after the implementation of a rapid access protocol. It remains to be seen if this reduction of 25 minutes from a median door-to-balloon time of 87 minutes (to $62 \mathrm{~min}$ ) represents a clinically meaningful advance in adult emergency cardiac care in our area. A greater proportion of patients was treated within the guideline-recommended 90 minutes. Most of the time savings achieved by this protocol, that is, a median reduction of 25 minutes, were in hospital ED times. Factors contributing to this reduction include the fact that the diagnosis was made in the field using prehospital 12-lead ECG and early ED notification, preparing the hospital for rapid treatment and transfer to the cardiovascular laboratory. Pending cardiovascular laboratory availability, patients were placed on portable monitors and remained on EMS stretchers for quick transfer. Staff awareness of the protocol and the importance of timely reperfusion resulted in more efficient care in both the ED and the cardiovascular laboratory (training effect). The protocol did not result in any significant delays in scene or transport times.

The protocol was not associated with a difference in complication rates. It had been felt possible that rapid transfer might result in unstable patients being transferred to the cardiovascular laboratory. The complication rate in both study groups was very low, so that it might be difficult to assess any change in outcomes from such (unstable) patients. Ideally, we would hope to see a lower rate of complication during these patients' hospital stay or in the first month after PCI. This longer term follow-up was not within the scope of this study.

Our study unfolded during a time of increasing interest in reorganizing currently available cardiac care resources in order to reduce time to reperfusion in STEMI patients. Recently, the Carolinas Medical Center in Charlotte, NC, demonstrated a very similar reduction in door-to-balloon

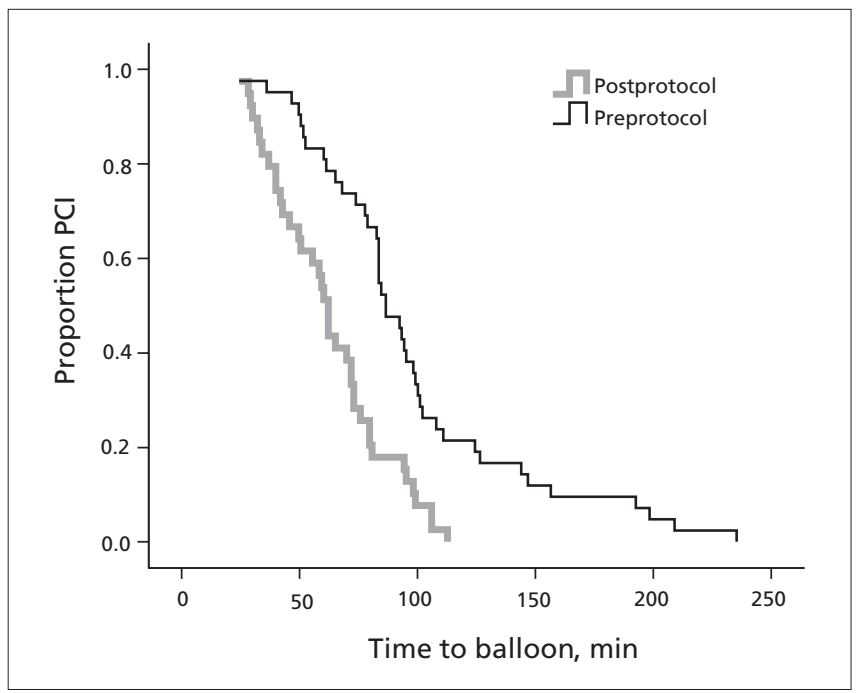

Fig. 1. Kaplan-Meier survival curve depicting door-to-balloon times before (second line) and after (first line) protocol implementation. $\mathrm{PCl}=$ percutaneous coronary intervention.

Table 2. Median time intervals from 911 call to first balloon inflation

\begin{tabular}{|c|c|c|c|}
\hline \multirow{3}{*}{$\begin{array}{l}\text { Interval } \\
911 \text { to scene arrivalt }\end{array}$} & \multicolumn{2}{|c|}{ Median time (IQR), min } & \multirow{3}{*}{$\frac{p \text { value }^{*}}{0.43}$} \\
\hline & Preprotocol & Postprotocol & \\
\hline & $6 \quad(4-13)$ & $(4-10)$ & \\
\hline Time at scene $\ddagger$ & $20(14-24)$ & $(18-25)$ & 0.16 \\
\hline Transport time§ & $8 \quad(5-15)$ & $(7-17)$ & 0.51 \\
\hline ED treatment and transitๆ & $63 \quad(47-83)$ & $\begin{array}{c}39 \quad(18-47) \\
9 * *(7-12)\end{array}$ & $<0.001$ \\
\hline Lab-to-balloontt & $27 \quad(21-32)$ & $(20-31)$ & 0.17 \\
\hline Door-to-balloon§§ & 87 (67-108) & $(40-80)$ & $<0.001$ \\
\hline Regular hours & 78 (53-99) & $(36-64)$ & \\
\hline After-hours & 97 (85-124) & $(57-83)$ & \\
\hline
\end{tabular}

$E D$ = emergency department; $I Q R$ = interquartile range.

* Difference by nonparametric rank sum (Mann-Whitney $U$ ).

tEmergency medical services (EMS) dispatch to scene arrival.

\#EMS scene arrival to departure.

§EMS depart scene to ED arrival.

TED arrival by EMS to cardiovascular laboratory arrival.

** Median time in ED for patients proceeding directly to the cardiovascular laboratory $(n=9 ; 7$ regular hours,

2 after-hours).

††Arrival at cardiovascular laboratory to first balloon inflating.

$\S \S E D$ arrival to first balloon inflation. 
times by implementing "Code STEMI," a prehospital diagnosis and bypass protocol analogous to the one examined in this study. ${ }^{22}$ Following implementation of a prehospital diagnosis and transfer pathway in Calgary, Alta., the median door-to-balloon time was reduced to 62 (IQR 45-84) minutes. ${ }^{23}$ The early success of similar protocols suggests that it may be possible to replicate these findings in other settings, despite regional variations in resource organization and patient populations. Researchers in Ottawa, Ont., have suggested that mortality is lower in STEMI patients triaged to the nearest PCI centre by advanced care paramedics in the field, compared with those who were transported by EMS to the nearest ED. ${ }^{21}$

\section{Limitations}

There are several limitations in this study. The primary weakness lies in the retrospective comparative study design. Although it would be optimal to compare outcomes using a prospective, randomized control trial, such a study would be difficult to implement. There was already evidence from small observational studies to support the use of rapid transfer protocols to reduce door-to-balloon times. ${ }^{21-23}$ While the collection of retrospective data are dependent on administrative accuracy, the data analyzed in this study (times) were objective and reliably collected. Our case identification was dependent on existing data systems. Although we searched multiple databases (NACRS, cardiovascular laboratory and hospital discharge) some cases may have been missed. We believe the final data set is as complete as was feasible. We chose a priori to exclude

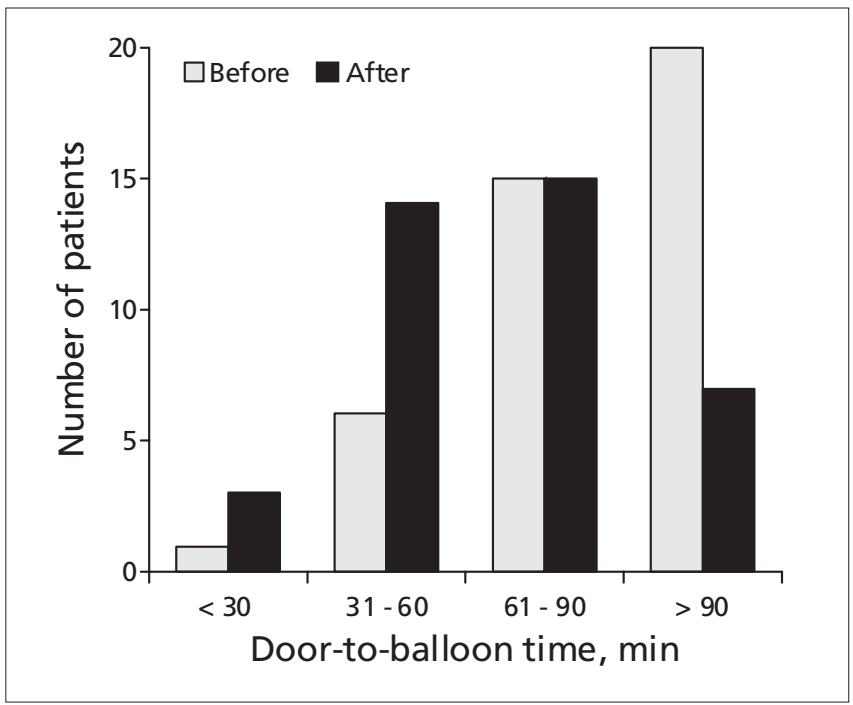

Fig. 2. Number of patients receiving percutaneous coronary intervention within the recommended 90-minute door-toballoon time before and after implementation of the rapid access protocol. patients that did not receive a complete PCI $(n=14)$. These patients may well have had poorer long-term outcomes. However, such long-term outcomes would not have affected our assessment of the primary outcome of interest (door-to-balloon time). Because paramedic training regarding the use of the rapid access protocol was ongoing during the preimplementation phase, there may be some contamination of the preprotocol group such that their times to PCI would be expected to approximate those in the postprotocol group. Two patients were managed under the protocol during this phase of the study. However, any bias introduced would be conservative to our results. Finally, our study presents results for a relatively small number of patients reflecting our community size. Despite this we were able to demonstrate statistically significant reduced doorto-balloon times after implementation of the rapid access PCI protocol.

\section{Conclusion}

In our region, implementation of an EMS protocol for rapid access to PCI significantly reduced time to reperfusion for patients with STEMI.

Acknowledgement: The authors thank Wilma Hopman for her assistance with statistical analysis.

Competing interests: None declared.

\section{References}

1. Heart and Stroke Foundation of Canada. Statistics. Ottawa $(\mathrm{ON})$ : The Foundation; 2008. Available: www.heartandstroke .on.ca/site/c.pvI3IeNWJwE/b.3581729/k.359A/Statistics.htm (accessed 2008 Nov 19).

2. Cannon CP. Time to treatment of acute myocardial infarction revisited. Curr Opin Cardiol 1998;13:254-66.

3. De Luca G, Suryapranata H, Ottervanger JP, et al. Time delay to treatment and mortality in primary angioplasty for acute myocardial infarction: every minute of delay counts. Circulation 2004;109:1223-5.

4. Sabatine MS, O'Gara PT, Lilly LS. Chapter 7. In: Lilly LS editor. Pathophysiology of heart disease. Baltimore (MD): Lippincott, Williams and Wilkins; 2003. p. 145-69.

5. Antman EM, Anbe DT, Armstrong PW, et al. ACC/AHA guidelines for the management of patients with ST elevation myocardial infarction: a report of the American College of Cardiology /American Heart Association Task Force on Practice Guidelines. Circulation 2004;110:e82-92.

6. Armstrong PW, Bogaty P, Buller CE, et al. The 2004 ACC/AHA Guidelines: a perspective and adaptation for Canada 
by the Canadian Cardiovascular Society Working Group. Can J Cardiol 2004;20:1075-9.

7. Keeley EC, Boura JA, Grines CL. Primary angioplasty versus intravenous thrombolytic therapy for acute myocardial infarction: a quantitative review of 23 randomised trials. Lancet 2003; 361:13-20.

8. McLellan CS, LeMay MR, Labinaz M. Current reperfusion strategies for ST elevation myocardial infarction: a Canadian perspective. Can J Cardiol 2004;20:525-33.

9. Bonnefoy E, Lapostolle F, Leizorovicz A, et al. Primary angioplasty versus prehospital fibrinolysis in acute myocardial infarction: a randomized study (CAPTIM). Lancet 2002;360:825-9.

10. Andersen HR, Nielsen TT, Rasmussen K, et al. A comparison of coronary angioplasty with fibrinolytic therapy in acute myocardial infarction. N Engl J Med 2003;349:733-42.

11. Luepker RV, Paczynki JM, Osganian S, et al. Effect of a community intervention on patient delay and emergency medical service use in acute coronary heart disease: the Rapid Early Action for Coronary Treatment (REACT) trial. JAMA 2000; 284:60-7.

12. Blohm M, Herlitz J, Hartford M, et al. Consequences of a media campaign focusing on delay in acute myocardial infarction. Am J Cardiol 1992;69:411-3.

13. Canto JG, Rogers WJ, Bowlby LJ, et al. for the National Registry of Myocardial Infarction 2 Investigators. The prehospital electrocardiogram in acute myocardial infarction: Is the full potential being realized? J Am Coll Cardiol 1997;29:498-505.

14. Morrison LJ, Brooks S, Sawadsky B, et al. Prehospital 12-lead electrocardiography impact on acute myocardial infarction treatment times and mortality: a systematic review. Acad Emerg Med 2005;13:84-9.
15. Whitbread M, Leah V, Bell T, et al. Recognition of ST elevation by paramedics. Emerg Med J 2002;19:66-7.

16. Bradley EH, Herrin J, Wang Y, et al. Strategies for reducing the door-to-balloon time in acute myocardial infarction. N Engl J Med 2006;355:1-13.

17. Leung RC, Lundberg DL, Rollefstad T, et al. From 911 to balloon: reduction of ischemic time in primary angioplasty by implementation of an expedited transfer pathway. CJEM 2005;7:183.

18. Daly PA. Management of STEMI in Canada: a report from Macstrak 1994-2006. Proceedings of the International Conference on Emergency Medicine; 2006 June 3-7; Halifax (NS): International Federation for Emergency Medicine; 2006.

19. Keeley EC, Hills LD. Primary PCI for myocardial infarction with ST-segment elevation. N Engl J Med 2007;356:47-54.

20. Bradley EH, Herring J, Wang Y, et al. Strategies for reducing the door-to-balloon time in acute myocardial infarction. $\mathrm{N}$ Engl J Med 2006;355:2308-20.

21. Lemay M, Dionne R, Davies RF, et al. Lower mortality in patients with ST-elevation myocardial infarction triaged in the field and referred for primary percutaneous angioplasty by advanced care paramedics. CJEM 2006;8:182.

22. Hancin B. Trauma approach slices STEMI treatment time. ACEP News 2006;25:1-2.

23. de Villiers JS, Anderson T, McMeekin JD, et al. Expedited transfer for primary percutaneous coronary intervention: a program evaluation. CMAJ 2007;176:1833-8.

Correspondence to: Dr. Jaelyn M. Caudle, Department of Emergency Medicine, Queen's University, 79 Stuart St., Kingston ON K7L 2V7; jaelyncaudle@hotmail.com 